\title{
Ensayos sobre acciones y sucesos
}

\author{
Jorge R. Tagle
}

\begin{abstract}
Davidson, Donald, Ensayos sobre acciones y sucesos, trad. del inglés por Olbeth Hansberg, José Antonio Robles y Margarita Valdés. México-Barcelona, Instituto de Investigaciones Filosóficas-UNAM/Crítica, 1995, 382 pp.
\end{abstract}

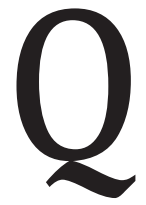
uizá no sea exagerado afirmar que algunos de los artículos reunidos en Ensayos sobre acciones y sucesos, originalmente en inglés Essays on Actions E Events (1980), son ya textos clásicos de la filosofía de este siglo Xx. Una parte nada desdeñable de la discusión contemporánea en filosofía de la acción, filosofía del lenguaje, metafísica, ontología, gira en torno, ya sea defendiendo, ya sea criticando fuertemente, a tesis y argumentos presentados por vez primera en los ensayos que componen dicho libro. Prueba de ello es que, no obstante que su contenido es relativamente reciente, su presencia en las revistas especializadas es constante y cuenta ya con varios volúmenes de ensayos consagrados a la discusión de las ideas defendidas en esas páginas. ${ }^{1}$ En lo que presento a continuación intento aprovechar hasta cierto punto toda la información que puede brindarme la tradición, la cual, por cierto, no es poca.

A simple vista podría surgir la impresión de que en el libro se reúnen escritos sin conexión alguna entre sí. Como prueba de ello se podría alegar que una mera colección de ensayos generalmente es señal de un conjunto de ideas, quizá muy interesantes y sugerentes, pero sin mayor afán de coherencia y sistematicidad. Pero una impresión de ese tipo respecto de Ensayos sobre acciones y sucesos sería algo totalmente equivocado. ¿Por qué? Porque a lo largo de los ensayos que componen el libro, tanto en lo que respecta a problemas como a las soluciones a esos problemas, existe unidad y un claro afán de sistematicidad. La primera creo que bien puede expresarse por medio de la

${ }^{1}$ Sin intentar proporcionar una lista exhaustiva a continuación menciono los siguientes: Bruce Vermazen y M. Hintikka, eds., Essays on Davidson: Actions and Events. Oxford, Oxford University Press, 1985; Ernest LePore y B. P. McLaughlin, eds., Actions and Events: Perspectivas on the Philosophy of Donald Davidson. Oxford, Blackwell, 1985; John Heil y Alfred Mele, eds., Mental Causation. Oxford, Clarendon Press, 1993. 
siguiente pregunta: ¿cómo debe explicarse la conducta intencional humana y cuáles son tanto los compromisos contraídos como las consecuencias filosóficas del modo escogido? A su vez esta pregunta puede desglosarse en las siguientes: ¿qué distingue a la conducta intencional de otros tipos de fenómenos?, ¿a partir de qué modelo debe explicarse la conducta intencional humana?, ¿qué papel pueden desempeñar ciertas intuiciones del sentido común en la explicación de la acción?, ¿qué tipo de ontología puede abrigar la existencia de acciones intencionales?, ¿cómo deben ser tratadas semánticamente las oraciones que expresan acciones?, ¿cuál es la forma lógica de las oraciones que expresan acciones? Puede decirse entonces que la unidad del libro la proporciona el tema de la filosofía de la acción y sus relaciones con la filosofía de la mente y la filosofía del lenguaje. El carácter sistemático del libro, por su parte, lo proporciona la perspectiva defendida por Davidson para la explicación de la conducta intencional humana, a saber, una que parte del vocabulario psicológico de deseos y creencias, de ciertos ideales presentes en dichos conceptos, de cierto uso del concepto de causa y de la causalidad, y de cierta ontología monista. A pesar de que en algunos momentos se sacrifica la consistencia de Ensayos sobre acciones y sucesos, pues hay modificaciones y correcciones en los ensayos más recientes de las ideas y argumentos defendidos en los anteriores, y a pesar de que a veces uno desearía un despliegue mayor de detalles, está

presente no sólo un enfrentamiento metódico con los aspectos epistemológicos, lógico-semánticos, metafísicos y ontológicos de la explicación de la conducta intencional humana, sino también el desarrollo de una propuesta sistemática que dé cuenta de los problemas antes expuestos.

La originalidad de Ensayos sobre acciones y sucesos radica en la argumentación y defensa de una epistemología de la explicación de la conducta intencional -junto con sus consecuencias y supuestos metafísicos y ontológicos- que, por una parte, intenta hacer justicia a ciertas intuiciones del sentido común, pero, al mismo tiempo, por otro lado, también busca aprovechar ciertas intuiciones respecto de cómo se produce la acción y a partir de qué se constituye. Davidson quiere reconciliar un par de perspectivas que tradicionalmente se habían pensado incompatibles: una perspectiva que pone el acento en la manera particular en que el sujeto percibe como se producen sus acciones y, por otra parte, una perspectiva que está convencida en considerar a la acción intencional humana como un fenómeno más que puede y debe ser explicado a partir de los conceptos y metodologías propias de las ciencias naturales. Davidson intenta desarrollar una vía intermedia que aproveche conceptos de una y otra tradición. Dicha de manera torpe y apresurada, una perspectiva de estudio de la acción intencional humana que reconoce la importancia y papel central de los contenidos mentales -con toda su racionalidad específica-del agente en cuestión para la 
producción y, debido a ello, la explicación de sus acciones, pero que piensa, al mismo tiempo, contrariamente a lo defendido por cierta tradición, que la relación entre los contenidos mentales y la acción específica es causal, entre relata con el mismo status ontológico, pero sin ser nomológica, sin implicar la existencia de leyes naturales estrictas. Davidson quiere tener racionalidad y causalidad sin que la una se coma a la otra. Después de presentar rápidamente cómo está estructurado temáticamente Ensayos sobre acciones y sucesos, regresaré a intentar precisar el esbozo anterior.

El contenido de Ensayos sobre acciones y sucesos de Davidson está integrado por varios núcleos, con intersecciones entre ellos. Uno es la teoría causal de la acción defendida principalmente, junto con otras muchas cosas que no comentaré, en la primera parte "Intención y acción"; en esta sección aparecen los ensayos "Acciones, razones y causas", “¿Cómo es posible la debilidad de la voluntad", "De la acción" (agency, en inglés), "Libertad para actuar" y "Tener la intención" (intending, en inglés). Otro núcleo es la semántica de las oraciones causales, de acciones, de sucesos, y de los adverbios, argumentada en la segunda parte "Suceso y causa", en particular en ensayos como "La forma lógica de las oraciones de acción" y "Relaciones causales". Un núcleo más está conformado por la ontología de sucesos, la cual es defendida en toda la segunda parte, en especial, en ensayos como "La individuación de los sucesos", "Los sucesos como particulares" y "Sucesos eternos vs. sucesos efímeros". El núcleo quizá más importante del libro está conformado por el conjunto de ensayos que aparecen en la tercera parte, "Filosofía de la psicología", y que defiende la tesis filosófica del monismo anómalo; los ensayos en cuestión son "Sucesos mentales", "La psicología como filosofía", "La mente material" y "Hempel y la explicación de la acción". Un último núcleo lo constituye un ensayo sobre "La teoría cognoscitiva del orgullo de Hume" en el cual se empiezan a desarrollar los elementos para una teoría que explique las emociones a partir de los deseos y las creencias de los individuos. A continuación me concentraré en algunos aspectos de los núcleos primero, tercero y cuarto de los arriba mencionados. Los núcleos restantes no los comentaré, pues el segundo habría que discutirlo en el contexto de la filosofía del lenguaje de Davidson, cosa que me es imposible hacerlo aquí; el núcleo quinto, por otra parte, no representa una propuesta acabada de Davidson, sino un mero atisbo, aunque quizá muy influyente, respecto de la naturaleza de las emociones. Su importancia, en comparación de los otros núcleos, es menor. El orden en que presentaré las ideas de Davidson no es aquel en el que aparecen en Ensayos sobre acciones y sucesos, sino uno que me parece más adecuado para poner de manifiesto la unidad y sistematicidad del mismo. Posteriormente a la presentación de cada uno de los núcleos escogidos, intentaré indicar algunas dificultades que insistentemente han sido señaladas a las tesis y argumentos ahí defendidos. 


\section{La ontología de sucesos}

Una de las propuestas más novedosas de Ensayos sobre acciones y sucesos radica en la argumentación y defensa de una categoría ontológica que, según Davidson, está indicada de varias maneras en el lenguaje natural. Además de distintas clases de objetos, piensa él, hay varias buenas razones para admitir que otro de los constituyentes básicos del mundo son los sucesos. ¿Pero qué es un suceso? La respuesta a dicha pregunta puede ser de dos tipos: criterialista (metodista) o particularista. Según el primer tipo se daría una definición que especificaría las características de todo suceso. Según el segundo tipo, se presentaría una lista de ejemplos de sucesos. ¿Cuál de los dos tipos escoge Davidson? Afortunadamente ambos; señala características y presenta ejemplos.

Desde una perspectiva particularista, sucesos son: la muerte de Monteverdi; la segunda entrevista al asesino de Trotsky; la tormenta en la ciudad de México la noche del 11 de mayo de 1994; la fiesta en el departamento de Enrique el fin de semana; la guerra en el golfo Pérsico; la presencia de Pedro en el restaurante para hacer una reservación; la explosión del drenaje en Guadalajara en 1993; el terremoto de 1985 en la ciudad de México; la preparación de la comida en casa de Pedro, etcétera. Las acciones intencionales, dirá Davidson, son una subclase de los sucesos. Más adelante abordaré este tema. Desde una perspectiva criterialista, un suceso es un cambio en el mundo, particular, irrepetible y fechado. Particular porque se refiere a una parte localizada del mundo o del universo y no al mundo o al universo en su conjunto; irrepetible porque sucede en un momento que jamás se repetirá; y, finalmente, fechado, porque se le puede ubicar en el tiempo. La muerte de Monteverdi, por ejemplo, fue un cambio de un elemento particular e irrepetible del mundo y sucedió en un momento específico.

Si particularidad, irrepetibilidad y ubicación temporal son características inteligibles, al menos intuitivamente, no pasa lo mismo con mutabilidad (cambio). ¿Por qué? Porque la noción de cambio remite directamente a la pregunta, ¿cambio respecto de qué? Y para contestar a ésta se requiere especificar algo de lo cual no siempre se dispone: los antecedentes causales (historia causal) del suceso en cuestión. Pues sólo de ese modo parecería que puede determinarse en qué momento ocurrió el cambio mencionado. Quizá otra dificultad sería que aparecieran varios candidatos igualmente admisibles a historias causales de un mismo suceso. El problema principal, sin embargo, con la postulación de sucesos es, como ha señalado Quine, que Davidson nos ha presentado una definición no circular de lo que es un suceso, pues se individua un suceso cuantificando sobre sucesos. Lo cual sólo es posible si previamente ya se han 
individuado los sucesos. Pero para ello se recurre a la cuantificación. ${ }^{2}$

La motivación principal para no desechar a los sucesos debido a estas dificultades proviene de nuestro lenguaje y nuestra práctica lingüística. Davidson mismo la indica claramente:

Las cosas cambian, pero ¿acaso hay cosas tales como los cambios? Se mueve un guijarro, nace una gacela, se derrumba un pedazo de tierra, explota una estrella. Además de guijarros y estrellas, ¿hay movimientos, nacimientos, derrumbes y explosiones? Nuestro lenguaje nos empuja a pensar que los hay al suministrarnos no sólo los términos singulares apropiados, sino el arsenal completo de artículos definidos e indefinidos, predicados clasificadores [sortal], conteo, cuantificación y enunciados de identidad; toda la maquinaria, tal parece, de la referencia. Si tomamos literalmente esta gramática, si aceptamos esas expresiones y oraciones como si tuvieran la forma lógica que parecen tener, entonces estamos comprometidos a aceptar una ontología de sucesos como particulares irrepetibles. (p. 231.)

Así pues, es la gramática de nuestro lenguaje, y en el fondo su forma lógica, la que exige la aceptación no sólo de objetos, sino de cambios en el mundo. Únicamente ellos pueden respaldar la verdad de oraciones que aluden a cambios en el mundo. En general, la respuesta a "¿por qué debe aceptarse una ontología donde se acepten cambios como valores de variables?”, es la siguiente: porque la teoría más importante de que disponemos los seres humanos, el lenguaje natural, contempla la existencia de, entre otras cosas, sucesos. ${ }^{3}$ Como toda motivación, debe confesarse, puede estar mal fundada, sin embargo, no deja de tener un razonable atractivo.

\section{La teoría causal de la acción}

Acciones: su intencionalidad en términos de creencias y actitudes favorables

${ }^{2}$ W. V. Quine, "Events and Reification", en Ernest LePore y Brian P. McLaughlin, eds., Actions and Events..., p. 166.

3 Véase. p. 232; y además, pp. 171-173. También en su "Reply to Quine on Events", en Ernest LePore y B. P. McLaughlin, eds., Actions and Events..., Davidson vuelve a esgrimir esta razón en favor de su ontología de sucesos. 
¿Cómo pueden existir acciones humanas intencionales en un mundo de puros sucesos? O bien, ¿qué convierte a un suceso en una acción humana intencional? Básicamente, que ese suceso sea realizado intencionalmente; así lo reconoce, aunque con reservas, Davidson: "Tropezarse con la alfombra no es normalmente una acción, pero lo es si se hace intencionalmente. Quizá, entonces, ser intencional es el rasgo distintivo pertinente". (p. 65.) Para ser más precisos: un suceso es una acción si y sólo si puede formularse bajo una descripción verdadera, relativa a la cual, además, es intencional. Lo que convierte a un suceso como café cayéndose al suelo en una acción es que alguien esté tirando (vaciando) intencionalmente ese café al suelo, y que esta descripción sea verdadera.

Antes de pasar a ver qué debe entenderse por hecho intencionalmente dentro de esta teoría, debo insistir en dos puntos: que las acciones son una subclase de los sucesos y que dependen estrechamente de la manera en que son descritas. Primero, las acciones, a pesar de ser tales, no dejan de ser sucesos, continúan siendo cambios o movimientos, nada más que, ahora, hechos con una intención. Segundo, algunos cambios o movimientos pueden ser descritos verdaderamente no sólo como sucesos sino también como acciones. La cuestión de si es uno u otra se decide del siguiente modo: si la descripción intencional de ese suceso es verdadera entonces puede afirmarse con justicia que es una acción; de lo contrario es un suceso. Un cambio o movimiento como el café cayéndose al suelo puede ser descrito de varias maneras, entre ellas, "el café se está cayendo al suelo", o "hay derrame de café", o "hay presencia de infusión de semilla de cafeto en las coordenadas $x, y, z$ en el momento $t$ ", o "Mario arroja su café al suelo". Si esta última es verdadera, entonces puede decirse que ese suceso es también, bajo esa descripción, una acción. El punto importante es, de cualquier modo, que la atribución de intencionalidad sólo es posible bajo una descripción. Si ésta es verdadera, entonces la atribución es correcta.

Ahora bien, ¿qué debe entenderse por actuar intencionalmente en este contexto? Al respecto Davidson es muy claro en el siguiente pasaje:

Alguien que actúa con cierta intención actúa por una razón; tiene en la mente algo que quiere promover o realizar. Un hombre que une con clavos dos tablas, con la intención de construir una casa de ardillas, debe querer construir una casa de ardillas, o pensar que debe hacerlo (sin duda por otras razones) y debe creer que unir con clavos dos tablas favorecerá su proyecto. Una referencia a otras actitudes, además de querer o pensar que debe, puede ayudar a especificar las razones del agente, pero parece que debe estar comprendida una actitud positiva $o$ favorable. (p. 107.) 
Cuando alguien realiza una acción con cierta intención, actúa por una razón; decir, pues, que un agente llevó a cabo ciertos movimientos con determinada intención quiere decir que los efectuó por una razón. ¿Qué es esta razón, en qué consiste?

[...] siempre que alguien hace algo por una razón, puede caracterizársele: (a) como si tuviera algún tipo de actitud favorable hacia acciones de una clase determinada, y (b) como si creyera (o supiera, percibiera, notara, recordara) que su acción es de esa clase. (pp. 17-18.)

Para seguir con el ejemplo antes citado, la razón se caracteriza por la creencia de que clavando algunas tablas se puede construir una casa de ardillas, y el querer, o pensar que se debería, construir una casa de ardillas clavando algunas tablas. Intención que refiere, en último término, a la creencia y la actitud favorable (pro-attitude) que guían al agente al realizar su acción. Pueden entrar otras consideraciones, pero, en su núcleo básico, una razón consiste de ambas actitudes proposicionales.

Actitud favorable - posteriormente Davidson la ha sustituido por deseosno debe entenderse como una actitud especial de los agentes; es únicamente un término general que debe ser sustituido en cada caso particular por una o varias de las siguientes actitudes:

Debe incluirse en (a) actitudes tales como deseos, impulsos, instintos, y una gran variedad de convicciones morales, principios estéticos, prejuicios económicos, convencionalismos sociales, metas y valores públicos y privados, en la medida en que éstos puedan interpretarse como actitudes del agente dirigidas a cierta clase de acciones.

La palabra "actitud" vale aquí para todo [...] (p. 18.)

Al dar la intención, la razón, se explica porque ese suceso es al mismo tiempo una acción. Pero, además, al exponer la razón también se explica porqué ocurrió tal acción. Ahora bien, ¿qué otra función está desempeñando aquí la razón?

\section{Acciones: su carácter causal}

Una de las contribuciones más importantes y originales de Davidson a la filosofía de la acción es la de considerar a la razón (intención) como la causa de la acción. Esto es, que entre ambas hay una relación causa-efecto: la razón es la 
causa de la acción. Así lo afirma Davidson: "La idea de que el agente realizó una acción porque tenía una razón es fundamental para la relación entre una razón y la acción que explica”. (p. 24). ¿Por qué te cortaste el cabello? Porque estaba demasiado largo y ya no podía acomodarlo. Así pues, porque quería peinarme sin dificultades fue que me corté el cabello. La acción, cortarse el cabello, es efecto del deseo de peinarse sin dificultades y la creencia de que cortándose el cabello puede conseguirse eso. Al reportar el por qué de una acción se está reportando su causa.

Para ser justos, esta idea no es una propuesta original de Davidson, pues, como él mismo reconoce: "en este ensayo quiero defender la posición antigua y de sentido común- según la cual la racionalización [la explicación de la acción que apela a la razón del agente] es una especie de explicación causal". (p. 17.) Sin embargo, su defensa de ella sí lo es. Las dos razones principales en dicha defensa son: la independencia lógica de razón (causa) y acción (efecto) y, el carácter no estrictamente nomológico de las explicaciones causales.

(a) La independencia lógica de razón y acción. Durante largo tiempo se consideró como un hecho indiscutible que entre razón (intención) y acción existe una relación lógica de mutua implicación: la una remite a la otra y viceversa. $O$, para ser más precisos, que no se le puede dar un sentido mínimamente inteligible a una sin remitirse necesariamente a la otra y viceversa. Tal tesis, afirma Davidson, posee su granito de verdad; pero eso no descarta la posibilidad de que causa y efecto sean lógicamente independientes. (Cf. pp. 2931.) Es común, afirma Davidson, que al hacer redescripciones inteligibles y correctas de una acción se pase por alto distinguir puntualmente a la intención de la acción o viceversa. Por ejemplo, en "por fin pude prender la luz", la descripción de la acción remite directamente a su intención y sólo es inteligible, por tanto, a la luz del deseo de encender la luz. Tal como está descrita, la acción es perfectamente inteligible y no se requiere de distinguir entre causa y efecto. También sucede que en muchísimas ocasiones es imposible llegar a comprender la intención de alguien sin tener presente, al mismo tiempo, la acción que satisface tal intención. "Quiero destapar esta lata y creo que con la ayuda de este puñal puedo conseguirlo", sería un buen ejemplo de una intención que, a primera vista, es un tanto desconcertante y que sólo al describir la acción - "he abierto la lata cortando una parte de la tapa con este cuchillo" - es comprensible. Otro caso muy común es que la descripción y la explicación de una misma acción puedan expresarse a través de un mismo medio, a saber, un silogismo práctico.

Davidson no rechaza lo anterior, de hecho acepta que el silogismo práctico es un buen indicador acerca de cómo llega un agente a considerar una acción como deseable, también admite que, muchas veces, la comprensión de la intención y la acción sólo es posible remitiéndose a ambas de manera simultánea, 
pero no acepta que todo eso sea una razón conclusiva en contra de la independencia lógica de razón y acción. ¿Por qué? Sus razones en contra de la tesis aristotélica que niega la independencia lógica de intención y acción son varias; a mi juicio, las siguientes son decisivas. Primera y obvia es que "describir un suceso en términos de su causa no es confundir el suceso con su causa, ni tampoco la explicación en términos de una redescripción excluye la explicación causal". (p. 30.) Esto es, al especificar la acción por medio de una parte de la descripción de la intención no se está confundiendo una y otra. Decir "yo deseaba destapar la lata y cré que utilizando el cuchillo lo conseguiría”, y que en dicha descripción de la razón vaya contenida una de la acción, se debe a razones gramaticales más que lógicas. Bien podrían especificarse la razón y la acción por separado: "deseo abrir la lata con este cuchillo" y "he abierto la lata", sin que exista relación alguna entre ambas descripciones. Esto remite a la segunda y más poderosa razón. Decir que no es posible separar lógicamente razón y acción es afirmar, entre otras cosas, que toda vez que un agente tiene una razón para actuar, lleva a cabo la acción correspondiente. Sin embargo, ¿no sucede a menudo que aunque se tenga la intención, no se actúa? Los ejemplos abundan: “deseo terminar lo más pronto posible de pintar la casa y creo que trabajando cuatro horas diarias durante una semana lo lograré", sin embargo, la acción no se lleva a cabo. "Deseo ayudar a mi prójimo y creo que donando esto lo puedo conseguir", sin embargo, la acción nunca se realiza. La incontinencia (akrasia) es también otro hecho cotidiano que, de algún modo, niega la tesis de la inseparabilidad lógica de razón y acción. Pues no conecta a la intención, la razón para actuar, con la acción pensada, sino con una distinta. En general, la existencia de intenciones "puras", de razones para actuar sin acción, es un argumento poderoso en contra de la inseparabilidad de razón y acción.

Debe reconocerse que estas "intenciones puras" pueden, al mismo tiempo, usarse como una razón en contra de la teoría causal. Se podría decir, por ejemplo, que las "intenciones puras" muestran que, en general, las razones no son suficientes por sí solas para mover a un agente a actuar. Luego, no son las verdaderas causas de la acción. ¿Qué decir de esto? Primero, de pensar así se estaría adjudicando un objetivo a la teoría davidsoniana que nunca afirma ni supone: pretensiones de suficiencia y necesidad. Esto es, se estaría adjudicando a la teoría causal la tesis de que es suficiente con saber la intención, para poder determinar que una acción va a ocurrir. Esta afirmación, a pesar de lo que podría pensarse en primera instancia, nunca es hecha por Davidson, pues no considera que su teoría deba establecer condiciones necesarias y suficientes para que ocurra la acción. Esto es, nunca piensa a su teoría con fines predictivos. Aún más importante, ésta no supone afirmaciones que la comprometan a tener que especificar condiciones necesarias y suficientes para que se produzca la 
acción. Lo que le interesa a Davidson, por el contrario, es explicar la relación entre razón y acción una vez que ya sucedió la segunda. Segundo, sería una mala decisión intentar buscar otros estados mentales cuya presencia garantizara que, una vez que se presentan el deseo y las creencias correspondientes, se producirá la acción. Pues esto puede, en el mejor de los casos, desencadenar un regreso al infinito respecto de estados mentales intermedios entre creencias + deseo y acción; en el peor de los casos, puede llevar a la postulación de estados mentales sui generis.

(b) El carácter no estrictamente nomológico de las explicaciones causales. Se ha defendido vigorosamente que cuando se explica algo causalmente se está apelando, en última instancia, a una ley natural. De ser verdadera esta creencia, sus consecuencias para la teoría causal de la acción serían inmediatas y graves. Pues, entonces, en toda explicación causal de la acción se estaría apelando, en último término, a una ley natural que correlaciona siempre la razón y la acción en cuestión. ¿Cuál es la respuesta de Davidson a esto? Afirmar que no es nomológicamente estricta la explicación causal. Hay casos donde, él reconoce, por supuesto está implicada una ley natural capaz de ser formulada en términos estrictamente científicos, pero eso no sucede en la conducta humana intencional. ¿Cómo defiende Davidson esta tesis?

Para la defensa de la no nomologicidad estricta de las explicaciones causales Davidson propone una interpretación novedosa del pasaje donde Hume afirma lo propio del concepto de causa y en general de la causalidad. De acuerdo a Hume, "podemos definir una causa como un objeto que es seguido por otro y tal que todos los objetos similares al primero son seguidos por objetos similares al segundo". ${ }^{4}$ Según Davidson, esta tesis humeana que históricamente ha sido interpretada como afirmando la identidad entre causalidad y nomologicidad estricta, puede ser interpretada como afirmando la existencia de leyes causales de dos modos no equivalentes:

[...] la tesis de Hume, tal como fue citada anteriormente, es ambigua. Puede significar que " $A$ causó $B$ " implica lógicamente alguna ley en particular que contiene los predicados usados en las descripciones " $A$ " y " $B$ ", o puede significar que " $A$ causó $B$ " implica lógicamente que existe una ley causal ejemplificada por algunas descripciones verdaderas de " $A$ " y " $B$ ". Obviamente ambas versiones de la doctrina de Hume confieren un sentido a la afirmación de que los enunciados causales singulares implican lógicamente leyes y ambas sustentan la tesis según la cual las explicaciones causales "suponen leyes". Pero p. 170 .

${ }^{4}$ D. Hume, A Treatise of Human Nature, 2a. ed. Oxford, Clarendon Press, 1978, 
la segunda versión es mucho más débil en el sentido de que una afirmación causal singular no implica lógicamente ninguna ley en particular y puede defenderse, de ser necesario, sin defender ninguna ley. Se pueden ajustar la mayoría de las explicaciones causales sólo a la segunda versión de la doctrina de Hume; se adecua igualmente a las racionalizaciones. (p. 33.)

¿En qué estriba la diferencia entre una y otra interpretación? En que mientras una afirma la existencia de una ley particular, propiamente formulada, que cubre ese caso particular y muchos más, la otra únicamente afirma que un caso particular podría implicar una ley cuya única instancia, descrita en un vocabulario común y corriente, es ese caso. Ejemplos: dentro de la primera interpretación estarían todas las leyes naturales que son confirmadas a cada momento. Dentro de la segunda interpretación entrarían enunciados causales singulares como: "debido a que José recibió la noticia de su amigo, soltó a llorar”. Por supuesto, en este último ejemplo está presente un enunciado causal singular del siguiente tipo: debido a $A$ ocurrió $B$. Otro ejemplo sería: "debido a una nota periodística acerca de la existencia de extraños ruidos nocturnos en un edificio del centro de la ciudad, la policía atrapó a una banda de desvalijadores de coches”. En este ejemplo también está presente un enunciado causal singular, luego, también está implicada una ley, de la cual la explicación causal es su única instancia verdadera. De cualquier modo, lo importante en los dos últimos ejemplos no es la ausencia de las supuestas leyes implicadas, sino su corrección y normalidad en tanto explicaciones de acciones.

Una explicación de la acción según el concepto de razón para actuar entendido como causa, donde la razón explique por qué un agente actuó como lo hizo, será llamada por Davidson racionalización. (p. 3.) Ésta explica la acción de un agente presentándola como algo razonable o justificado a la luz de los deseos u obligaciones que el agente se ha señalado. Aquí se tiene, por tanto, la combinación mencionada en los primeros párrafos: creencias, deseos, en general, contenidos mentales con su racionalidad específica, y discurso causal no estrictamente nomológico. La acción se produce debido a los contenidos mentales del agente, éstos funcionan como sus causas, y, la explicación de la misma sólo es posible apelando a ellos mismos. Sólo las creencias, deseos, etcétera, del agente nos presentan sus acciones como algo inteligible. ¿Qué decir de esta teoría causal de la acción?

Por lo pronto, un problema serio al cual se enfrenta la teoría causal de la acción lo constituye la existencia de cadenas causales desviadas ("deviant causal chains"). Esto es, la existencia de sucesos (entre ellos, acciones) producto de otros sucesos, pero no de aquel o aquellos que uno esperaría regularmente. Un ejemplo para ilustrar esto puede ser lo siguiente: Pedro tiene el deseo de 
encontrarse con un viejo amigo y piensa que si va al lugar de trabajo de su amigo podrá reunirse con él; efectivamente Pedro acude al lugar de trabajo de su amigo. En dicho lugar se le informa que su amigo ya no labora allí desde hace varios meses. Sin embargo, por un afortunado accidente, Pedro encuentra a su amigo, pues éste había acudido a su antiguo lugar de trabajo a finiquitar algunas deudas. Así pues, por un afortunado accidente, y no debido a su intención, es que Pedro lleva a cabo el encuentro con su amigo. O mejor dicho, Pedro tiene su intención, se produce el encuentro deseado, y, no obstante, no es debido a aquella que se produce el encuentro. Algunos esfuerzos se han llevado a cabo intentando salvar a la teoría causal de la acción de este escollo; Davidson mismo, por su parte, en un artículo aparecido pocos años después de la publicación de Ensayos sobre acciones y sucesos, ha llegado a afirmar que los conceptos de suceso, causa e intención son inadecuados para explicar a la acción intencional. ${ }^{5}$ Desde mi punto de vista, Davidson le ha otorgado demasiada importancia a la existencia de cadenas causales desviadas, pues aunque son recurrentes, no pueden ser la regla. Pues sólo podemos decir que son desviadas con el trasfondo de casos que no lo son. Si la excepción se convierte en regla, como Davidson parece admitirlo en su desalentadora afirmación, entonces qué sentido tiene hablar de una distinción entre casos normales y casos desviados. Seguramente el lector, después del estudio de todo este material, podrá llegar a formarse un mejor juicio al respecto.

\section{El monismo anómalo}

Tanto la explicación causal de la acción como la ontología de sucesos pueden tener una interpretación que, a pesar de lo que intenta sostener la primera, compromete a cualquier exponente de ambas a defender no sólo un monismo ontológico como propugna la ontología de sucesos sino también una metodología estrictamente naturalista para la explicación de la conducta intencional humana. Davidson, como ya se ha visto, busca defender una vía intermedia entre las perspectivas aristotélica y naturalista: aprovecha el vocabulario de creencias, deseos y pensamientos del sujeto de la acción y también emplea el discurso causal. Una primera aproximación a sus razones en favor de esta vía intermedia radica en su defensa, como ya se vio, de cierto sentido no estrictamente nomológico de causa y causalidad. Otra manera de defender esta vía intermedia la constituye su monismo anómalo. En éste Davidson busca demostrar la com-

${ }^{5}$ D. Davidson, "Problems in the Explanation of Action", en P. Pettit, R. Sylvan y Norman, eds., Metaphysics and Morality: Essays in Honour of J. J. C. Smart. Oxford, Blackwell, 1987. En este artículo Davidson indica algunos artículos donde se ha intentado solucionar el problema de las cadenas causales desviadas. 
patibilidad de una ontología monista que sólo admite la existencia de un sólo tipo de sustancia -sucesos particulares y objetos físicos-sujeta a leyes causales estrictas, con la existencia de todo un cuerpo de conceptos y conocimientos regulado por normas y consideraciones de racionalidad. Davidson piensa que no es incoherente defender, por una parte, que el mundo está compuesto de un solo tipo de sustancia, la cual es el objeto de investigación y tema del discurso de las ciencias naturales, $y$, por la otra, que tenemos todo un saber compuesto de conceptos, conocimientos y racionalidad que no es reducible al discurso de las ciencias naturales. Esto que he caracterizado apresurada y torpemente, Davidson lo empieza a desarrollar a partir de los tres principios siguientes:

El primer principio afirma que por lo menos algunos sucesos mentales interactúan causalmente con sucesos físicos (podemos llamar a éste el Principio de Interacción Causal). [...]

El segundo principio dice que donde hay causalidad debe haber una ley: los sucesos relacionados como causa y efecto caen bajo leyes deterministas estrictas (podemos llamar a éste el Principio del Carácter Nomológico de la Causalidad). [...]

El tercer principio es que no hay leyes deterministas estrictas con base en las cuales puedan predecirse y explicarse los sucesos mentales (la Anomalía de lo Mental). (pp. 264-265.)

A muchos pueden parecerles incompatibles entre sí estos tres principios, esto es, puede resultarles imposible aceptar los tres conjuntamente y afirmar, además, que son perfectamente consistentes entre sí. Según Davidson, son perfectamente compatibles y podemos aceptarlos sin titubeo alguno. Los tres, dirá él, caracterizan una posición metafísico-ontológica perfectamente consistente. ¿Quién tiene la razón? A continuación intentaré caracterizar lo mejor posible la posición de Davidson y, después, indicaré algunas dudas respecto de la viabilidad de dicha posición.

El primer principio, el de la interacción causal, y una parte del segundo, el carácter nomológico de la causalidad, creo que es difícil ponerlos en cuestión. El primero está apoyado en un hecho cotidiano: sucesos físicos causan sucesos mentales y viceversa. La explosión en la fábrica de productos químicos causó mi creencia en que explotó una fábrica, sería un ejemplo fácil de multiplicar respecto de causalidad de lo físico a lo mental. Mi decisión de visitar a mi amigo es la causa de mi presencia en su casa, sería un ejemplo igualmente fácil de multiplicar respecto de causalidad de lo mental a lo físico. Este primer principio posee una fuerza intuitiva difícil de contrarrestar. El carácter nomológico de la causalidad, que ya fue discutido al presentar la teoría causal de la acción, también puede aceptarse, siempre y cuando se 
tenga presente la distinción entre nomologicidad estricta (leyes naturales explícitas y formuladas en un vocabulario estrictamente físico) y nomologicidad no estricta (enunciados causales formulados en un vocabulario no estrictamente físico). Así pues, todos los sucesos, estén descritos en términos mentales o en términos físicos, pueden estar sujetos a leyes, sin que con ello se haya dicho gran cosa al respecto.

El tercer principio, el de la anomalía de lo mental, es el que, a la luz de los dos anteriores, causa cierta perplejidad, pues parece negar aquello que precisamente ya se aceptó en los dos anteriores, a saber, que los sucesos interrelacionados, sean físicos, sean mentales, se comporten de manera legaliforme. Decir que "no hay leyes deterministas estrictas con base en las cuales puedan predecirse y explicarse los sucesos mentales" es francamente decir lo contrario de lo afirmado en el segundo principio: "los sucesos relacionados como causa y efecto caen bajo leyes deterministas estrictas". Por un lado se afirma que sí hay sucesos interrelacionados como causa y efecto, no importa si son físicos o mentales, su comportamiento se explica a partir de la existencia de leyes deterministas estrictas, por otro lado, se afirma que los sucesos mentales, los cuales ya estaban contemplados en el principio anterior, no caen bajo leyes deterministas estrictas. ¿No es esto una clara contradicción? ¿No se acepta y rechaza al mismo tiempo el mismo enunciado? Según Davidson, éste no es el caso y, después de hacer ciertas precisiones, los tres principios se revelan como perfectamente compatibles.

Las aclaraciones, según Davidson, indispensables para conciliar a los tres principios que caracterizan su posición ontológico-metafísica son, básicamente, dos. La primera aclaración radica en distinguir entre generalizaciones homonómicas y heteronómicas. De manera esquemática puede decirse que una ley natural estricta surge a partir de una generalización en el comportamiento de dos sucesos relacionados como causa y efecto. Esta generalización, a su vez, puede ser de tipo homonómico o de tipo heteronómico. ¿En qué radica la diferencia? En que la primera está formulada en un vocabulario cercano al de las leyes naturales estrictas descubiertas por las distintas ciencias naturales. El segundo tipo de generalización también apunta a la existencia de alguna ley específica pero lo hace en un vocabulario poco familiar a aquel en el cual se expresan las leyes naturales en las distintas ciencias. La enunciación de este segundo tipo de generalizaciones es tal que si se quiere sacar a la luz la ley natural ahí implícita habrá que cambiar de vocabulario. Dice Davidson:

Por una parte, hay generalizaciones cuyas instancias positivas nos dan pie para creer que la generalización misma podría mejorarse añadiendo otras estipulaciones y condiciones formuladas en el mismo vocabulario general que la generalización original. Tal generalización apunta a la 
forma y al vocabulario de la ley acabada: podemos decir que es una generalización homonómica. Por otra parte, hay generalizaciones que, instanciadas, pueden darnos razón para creer que se está trabajando con una ley precisa, pero que sólo puede enunciarse si cambiamos a un vocabulario diferente. Podemos llamar heteronómicas a tales generalizaciones. (p. 278.)

Esta aclaración empieza a indicar una diferencia crucial al interior de los candidatos a leyes naturales estrictas. Hay algunos que, con un poco más de elaboración, seguramente se convertirán en leyes naturales estrictas. Sin embargo, hay muchos otros que sólo podrán llegar a adquirir ese status si se les trabaja con otro tipo de vocabulario y metodología. Hasta aquí, un simpatizante de la causalidad nomológica estricta podría decir que nada se ha hecho para quitarle lo contradictorio a los tres principios que caracterizan al monismo anómalo; pues no se ha dado ninguna razón en contra de que todas las generalizaciones heteronómicas pasen a ser generalizaciones homonómicas, y, a partir de allí, a ser leyes naturales estrictas. Por consiguiente, nada se ha dicho que pueda reconciliar al tercer principio con los dos primeros. Aquí entra la segunda aclaración de Davidson.

¿Hay alguna razón en contra de la conversión de las generalizaciones heteronómicas en generalizaciones homonómicas? Davidson piensa que sí, y es una tan poderosa como para haber sido defendida por Kant sin vacilaciones. Davidson piensa que el costo de convertir a las generalizaciones heteronómicas en generalizaciones homonómicas es que éstas dejen de ser lo que son; cosa que a alguien le puede parecer deseable pero que, defiende Davidson, iría, en última instancia, en contra de nuestra concepción misma de seres humanos racionales y libres. Si las generalizaciones heteronómicas llegan a convertirse en generalizaciones homonómicas y, luego, en leyes naturales estrictas, eso radicaría, básicamente, en cambiar de manera de presentarse, de vocabulario en el cual están formuladas. Pero, puede volver a preguntarse, ¿realmente puede hacerse esto? Davidson piensa que no, pues el vocabulario en el cual están formuladas las generalizaciones homonómicas y las leyes naturales estrictas es muy diferente al vocabulario donde están formuladas las generalizaciones heteronómicas, las cuales, por cierto, son la gran mayoría y constituyen "la mayor parte de nuestro saber práctico (y científico)”. ¿Dónde radica la diferencia entre ambos vocabularios? ¿Por qué son irreductibles? La diferencia fundamental es que ambos vocabularios obedecen a ideales distintos, uno busca la regularidad físicamente descrita mientras que el otro busca hallar racionalidad en los fenómenos.

No hay leyes psicofísicas estrictas debido a los compromisos dispares de 
los esquemas físico y mental. Una característica de la realidad física es que el cambio físico puede explicarse mediante leyes que lo conecten con otros cambios y condiciones descritas físicamente. Una característica de lo mental es que la atribución de fenómenos mentales debe ser responsable [estar avalada] ante el trasfondo de las razones, creencias, e intenciones del individuo. No puede haber conexiones estrechas entre las áreas si cada una mantiene fidelidad a su propia fuente de evidencia. [...] cuando usamos los conceptos de creencia, deseo y demás, debemos estar preparados, conforme la evidencia se acumula, para ajustar nuestra teoría a la luz de consideraciones de cohesión [inteligibilidad] total: el ideal constitutivo de racionalidad controla parcialmente cada fase de la evolución de lo que debe ser una teoría en desarrollo. [...] el debilitamiento nomológico entre lo mental y lo físico resulta esencial en tanto que concebimos al hombre como animal racional. (pp. 281-282.)

Davidson, pues, concede el punto de que todas las relaciones causales abrigan leyes estrictas, pero presenta una razón bastante poderosa en contra de que puedan ser formuladas y utilizadas: el funcionamiento distinto e irreductible del ámbito y el vocabulario de las generalizaciones homonómicas y las leyes naturales estrictas, y del ámbito y el vocabulario de los enunciados causales singulares y las generalizaciones heteronómicas. Un ámbito responde a los ideales naturalistas de la formulación de leyes expresadas por fórmulas y ecuaciones matemáticas, mientras que el otro responde al ideal de la racionalidad y autonomía. No se niega la existencia de leyes estrictas, pero sí la posibilidad de llegar a reducir el vocabulario común y corriente a puro vocabulario científico. Insistir en la formulación de leyes estrictas que intenten reducir cualquier tipo de explicación causal al estrictamente legaliforme, es, dirá Davidson, o bien abandonar el ideal constitutivo de racionalidad o bien cambiar de tema. Esto es, o bien olvidarse de los ideales de racionalidad que le dan sentido a nuestras vidas y a la manera en que las concebimos y explicamos, o simplemente empezar a hacer otra cosa en lugar de dar explicaciones que nos interesan, sirven y orientan en nuestra vida cotidiana.

Davidson piensa que una vez hechas estas precisiones es más fácil apreciar la compatibilidad entre los tres principios arriba enlistados y, por ello, aceptar su monismo anómalo, su teoría causal de la acción y, en general, su teoría de la explicación de la conducta intencional humana. En suma, se pueden tener enunciados que afirmen relaciones causales entre sucesos, mentales o físicos, leyes naturales estrictas que expliquen esas relaciones causales, y anomalía de lo mental, pues el funcionamiento del discurso mental no puede ser especificado mediante leyes naturales. 
Como muchos, pienso que Davidson ha presentado y defendido muy inteligentemente algo que todos quisiéramos tener junto. Libertad y autonomía, por una parte, y necesidad por la otra. Sin embargo, al igual que muchos otros, no dejo de preguntarme, ¿realmente ha logrado conciliar todo eso? ¿No hay dificultades que se nos escapan por el entusiasmo de ver junto todo lo que deseamos? Por lo pronto, dos problemas que se le han señalado a estas ideas y argumentos son los siguientes. Primero, la ineficacia causal de lo mental y, segundo, debido a lo anterior, la subsumibilidad última de toda explicación causal en alguna explicación legaliforme estricta. ${ }^{6}$ Para plantear la primera dificultad es necesario traer a colación una tesis davidsoniana no considerada hasta aquí, a saber, la superviniencia de lo mental a partir de lo físico. Según esta tesis, todas las características mentales dependen de características físicas. En palabras de Davidson:

[...] las características mentales dependen en cierto sentido de, o supervienen en, las características físicas. Tal superviniencia podría tomarse en el sentido de que no puede haber dos sucesos iguales en todos sus aspectos físicos pero diferentes en algún aspecto mental, o de que un objeto no puede alterarse en algún aspecto mental sin que se altere en algún aspecto físico. La dependencia o superviniencia de este tipo no implica lógicamente reductibilidad mediante una ley o definición [...] (pp. 272-273.)

La dificultad planteada por la ineficacia causal de lo mental consiste en afirmar que los sucesos mentales son eficaces sólo en tanto supervienen de sucesos físicos; el poder causal que pueden llegar a tener proviene de su superviniencia de sucesos físicos. Debido a ello, en tanto sucesos mentales, las creencias, deseos, intenciones, decisiones, etcétera, son inertes, incapaces de producir efecto alguno. Davidson ha intentado responder a esta crítica señalando que los sucesos son eficaces en tanto sucesos, independientemente de esta o aquella descripción. ${ }^{7}$ La segunda objeción, que depende estrechamente de la fuerza de la objeción anterior, afirma que, a pesar de lo que dice Davidson al final del pasaje anteriormente citado, deben buscarse leyes o definiciones del vocabulario mental en términos de un vocabulario estrictamente físico. Ya sean leyes naturales estrictas que nos digan cómo se comporta lo mental o, en todo caso, definiciones de los términos mentales a partir de un vocabulario que haga uso esencial y exclusivo de predicados de alguna ciencia física. ¿Por qué? Porque si toda característica mental depende enteramente de características físicas para

${ }^{6}$ La argumentación de ambas dificultades debe mucho a los trabajos de Jaegwon Kim. Véase en especial sus ensayos reunidos en J. Kim, Supervenience and Mind. Cambridge, Cambridge University Press, 1993; y sus artículos en el volumen colectivo editado por John Heil y Alfred Mole, Mental Causation. 
existir y tener poder causal, entonces, en última instancia, todo discurso mental no es más que discurso físico disfrazado y debe poder ser reductible a discurso físico. Así sólo sea gradualmente, debe poder ser expresado en un vocabulario que haga uso exclusivo de predicados de alguna de las ciencias físicas. Porción tras porción del discurso mental, dirán los reductivistas o los eliminativistas, será traducida al vocabulario de la ciencia natural. El tercer principio, dirán éstos, choca irremediablemente con los dos primeros, por ello, hay que abandonar el tercero si se quiere defender una posición metafísico-ontológica consistente. Desarrollar y evaluar debidamente ambas objeciones, en particular, qué tan factible sea esta propuesta reductivo-eliminativista y qué tanto responde a los ideales e intereses presentes en el dominio que busca reducir o desaparecer, son cuestiones que me llevarían más allá de los límites de una reseña; dejo al lector interesado ambas tareas.

¿Qué decir del propósito davidsoniano de hacer compatibles ambas tradiciones para la explicación de la conducta intencional humana? Por lo pronto, que las tesis y los argumentos mediante los cuales busca llevarlo a cabo son enormemente interesantes, sutiles y profundos. Respecto de su verdad, el lector podrá emitir su juicio una vez que los haya estudiado detenidamente junto con sus objeciones. Finalmente, hay que felicitar a los traductores por su trabajo y por poner a disposición del lector hispanohablante una contribución clave de la filosofía contemporánea.

${ }^{7}$ Para todos los detalles respecto de esta respuesta de Davidson al cargo de hacer inerte a lo mental, véase, Davidson, "Thinking Causes" en J. Heil, y A. Mele, eds., Mental Causation. 